\title{
Digital economy: Securing the future
}

Written by: Andy Wyckoff, Director, OECD Directorate for Science, Technology and Innovation

Last update: 28 January 2020

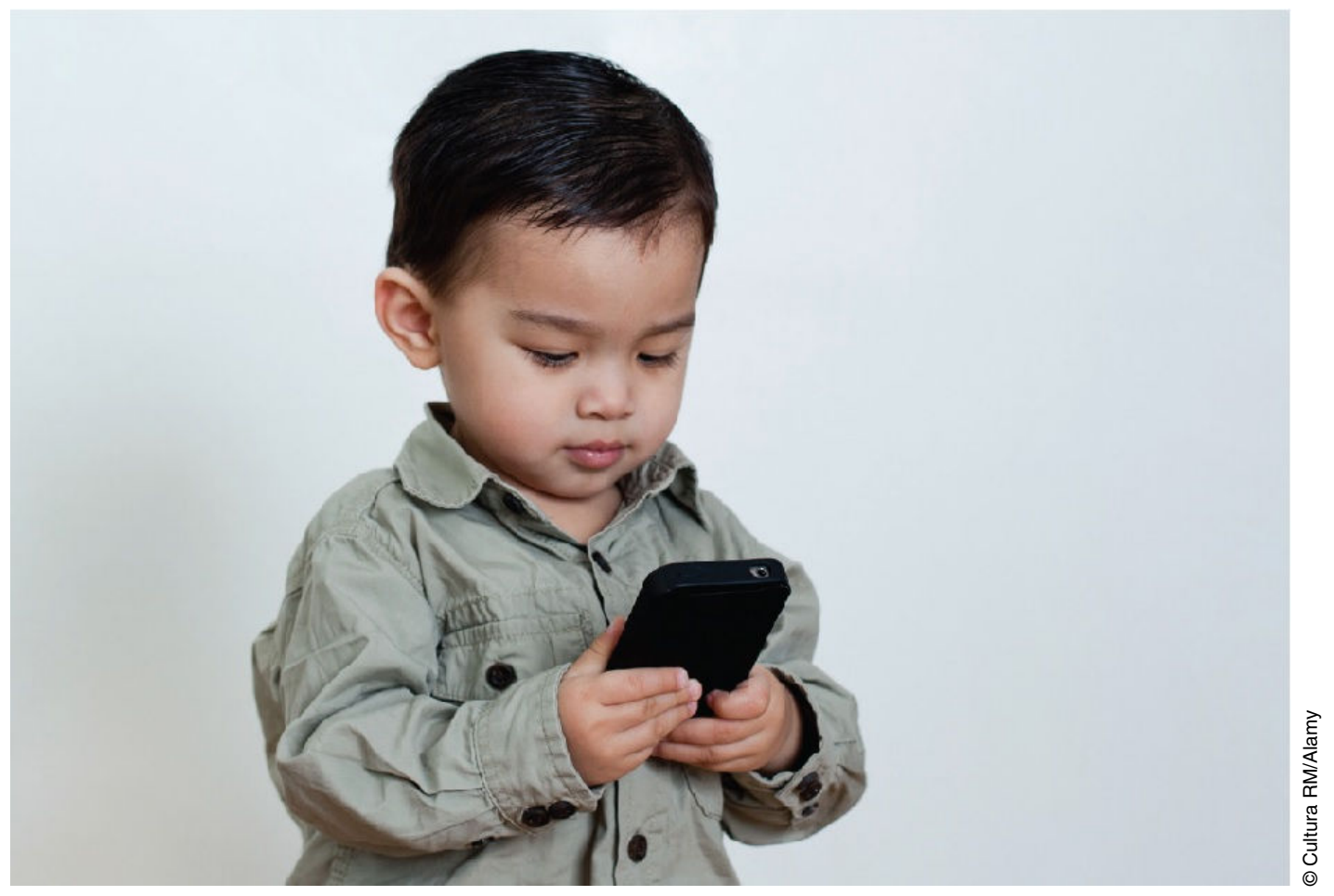

The digital economy is here, and growing every day, sometimes in surprising ways. As ministers at major meetings in Paris and Cancun expressed, government leaders should be in no doubt about the key role they must play in securing the digital economy's future as a driver of productive and inclusive progress.

"Analysing the impact of electronic commerce in 1997 is about as easy as estimating the impact of the automobile in 1900. Intuitively you know that the impact will be large, but few people know how to drive, roads are of varying quality and gas stations and mechanics are nearly non-existent. With some confidence you can say that there will be a positive impact on supplying industries such as oil, steel, glass and rubber, and direct competitors like horses, oat producers and carriages are likely to suffer, but beyond that it is largely speculation. Who would have predicted that the car would lead to suburbs, air 
pollution and the geo-political importance of the Middle East? So it is with electronic commerce." (OECD Observer, No 208 1997, see references).

So I wrote, in a contribution to the OECD Observer magazine in 1997 during the run-up to the first ever OECD ministerial meeting devoted to the digital economy, held in Ottawa, Canada in 1998. How prescient that meeting proved to be: not only was it the year the Internet was colonised (indeed, privatised), albeit by just 2 million domain names (including www.oecd.org), but it was also the year that a firm called Google was incorporated, while barely a year after that, a company calling itself Amazon had an initial public offering.

Nearly two decades later, the OECD organised another ministerial meeting, this time in Cancun, Mexico, under the title: "Digital Economy: Innovation, Growth and Social Prosperity." Extending the automobile metaphor, we now drive at speeds more than a thousand times faster than we did on the 1998 "information highway"; we've gone from a mere 180 million "drivers" (about $3 \%$ of the world population) to over 3 billion (40\%). Seatbelts, let alone airbags, don't exist yet, but GPS is here following us wherever we go and our "cars" now fit in our pocket.

Like the suburbs, digital technologies have sprawled into nearly every part of the economy and society : $80 \%$ of OECD citizens have broadband subscriptions with the majority accessing the more than 300 million websites

Like the suburbs, digital technologies have sprawled into nearly every part of the economy and society via a smartphone. Some $95 \%$ of 16-24 year olds in the OECD use the Internet and on average a 15-yearold spends three hours a day online, while about half of OECD citizens now engage in e-commerce.

Clearly, the goal at Ottawa to "realise the potential" has been achieved-the digital platform is well deployed across most of the OECD and quite a bit beyond too, while applications extend into every facet of the economy and society, disrupting and enhancing many sectors along the way and unleashing innovation, productivity growth and (as yet unmeasured) social benefits. Newspapers, music, finance and travel agents have been transformed, in some ways as predicted, though Facebook, Twitter, smartphones and the "sharing economy" have perhaps surpassed people's expectations, even disrupting established structures and economic arrangements. Many innovations were simply beyond our imagination: who could have guessed that we'd be experimenting with automated vehicles in 2016 ?

Some pundits say the big economic impact of information and communication technologies (ICT) may have already passed as we harvested the low-hanging fruit of computerisation in the second half of the 1990s. Others think that we are just at the beginning of another wave, characterised by ubiquitous computing as epitomised by the smartphone, which is both a platform and a linked device par excellence. It is the harbinger of the Internet of Things, expected to encompass 
between 20 and 50 billion devices connected to the Internet by 2020, throwing off torrents of data and supporting our daily routines. Already, more data are now being generated every week than in the last millennia, as our chart shows.

Crucially, the ability to analyse this data and extract strategic insights has made huge advances, with new data analysis techniques making it possible to automate decision making (e.g. high-speed trading) and edge towards artificial intelligence (AI). All of the major Internet platforms as of 2016, including Google, Amazon, Microsoft, Facebook, Apple, etc, now see AI as the we are just entering a significant period of ICTinduced structural change that will simply transform the economy and society for the better. We have

seen nothing yet. next big service that users will demand and already have applications, such as face and voice recognition. Many, including this author, think that we are just entering a significant period of ICT-induced structural change that will simply transform the economy and society for the better. We have seen nothing yet.

But this techno-optimism needs to be tempered with a reality check, that not all these advancements are universally welcomed. Some people worry about technology taking our jobs, others about privacy and data issues, while there is a more widespread erosion of trust fuelled by security breaches, including the Snowden revelations and abuse of the Internet by the "dark side" (terrorists and criminals). Policy makers must take these concerns seriously and develop policies to mitigate the risks and unleash the benefits.

\section{Productivity's macro-puzzle}

Another challenge is productivity growth. True, this has slowed in recent years and many people still refer to Robert Solow's 1987 remark that computers are everywhere except in the productivity statistics. But three decades on, and the data we have been gathering on quite a number of firms and industries clearly show that the digital economy does indeed benefit productivity via several channels: by generating new innovative enterprises and clearing out old, badly performing, ones in a process of creative destruction; by allowing smarter, more efficient use of labour and capital to generate so-called multi-factor productivity growth, whereby even older firms can raise their game; by introducing new opportunities and services among people previously removed from the global economy, such as farmers, and local manufacturers and public services; by enhancing information efficiencies to improve stock management and shipping, for instance; the list goes on. Why all these "micro" increases in productivity do not add up to faster productivity growth at the "macro" level is a puzzle that the OECD is working to solve. 


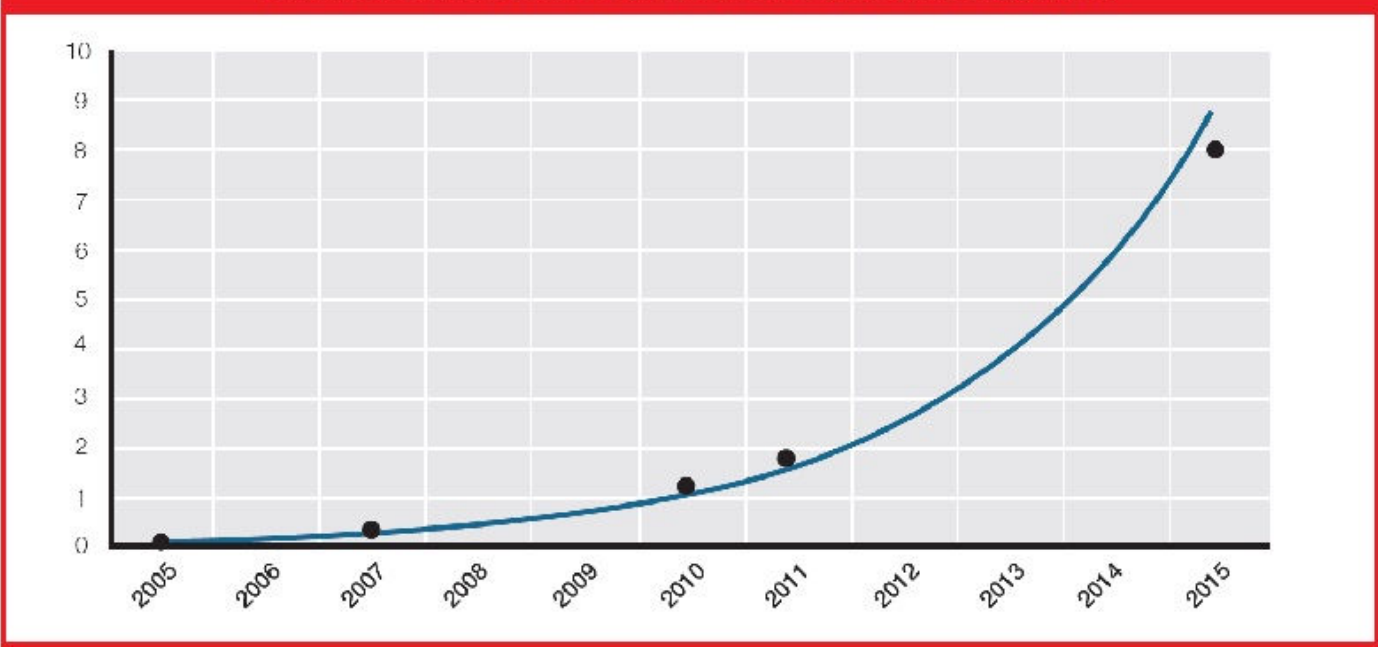

Clearly, the online world is at another inflection point, and it could go in more than one direction. That is why stakeholders at the international meeting in Cancun-from government, business, labour, civil society and the technical community-not only took stock, but took a step back to assess the big picture. Where is the digital economy going, and how can policy help it deliver on even greater promise in the years ahead?

No one is in doubt about the transformative role of ICT. It is neither an infant in need of protection, nor a teenager that needs oversight, but a young adult who needs to shoulder responsibilities and take its rightful place in the world. The agenda's four main themes therefore reflected what is needed to plot the way ahead: Internet Openness and Innovation; Building Global Connectivity; Trust in the Digital Economy; and Jobs and Skills in the Digital Economy. The digital economy is a powerful catalyst, and a driver of inclusiveness, by linking communities to each other in a sort of "global village", sharing information, ideas and products, and allowing countries to rise up the value chain. It must be allowed to grow, by allowing our "young adults" to sow economic and social opportunities for more and more citizens. For a few days in June, Cancun became the centre of that global village, where a new chapter in the collective future for the digital economy and society can begin.

@OOECD Yearbook 2016

Wyckoff, Andy (1997), "Imagining the impact of electronic commerce" in OECD Observer No 208, Oct-Nov, available at www.oecd-ilibrary.org, at http://oe.cd/1ln

Visit www.oecd.org/sti/innovation-imperative.htm

Find out more about "The Digital Economy: Innovation, Growth and Social Prosperity", OECD Ministerial Meeting, Cancun, Mexico 21-23 June, www.oecd.org/internet/ministerial/meeting/ 
Read the Cancún Ministerial Declaration on the Digital Economy at: http://oe.cd/ Digital-Economy-Cancun-Declaration-2016

Read the OECD's summary of the 2016 Ministerial Meeting on the Digital Economy http://oe.cd/Digital-Economy-Cancun-Summary-2016 http://oe.cd/1nj 